\title{
Papillary Carcinoma of the Penis, Not Otherwise Specified
}

National Cancer Institute

\section{Source}

National Cancer Institute. Papillary Carcinoma of the Penis, Not Otherwise Specified. NCI

Thesaurus. Code C103340.

A low-grade, well differentiated squamous cell carcinoma that arises from the penis. It is characterized by the presence of papillary architectural patterns and hyperkeratosis. It is not associated with human papillomavirus infection. 